\title{
An analysis of relaparotomy in operative obstetrics
}

\author{
Archana Kumari*, Anubha Vidyarthi
}

Department of Obstetrics and Gynecology, Rajendra Institute of Medical Sciences, Ranchi, Jharkhand, India

Received: 01 April 2020

Accepted: 07 April 2020

\section{*Correspondence:}

Dr. Archana Kumari,

E-mail: dr_karchana@yahoo.co.in

Copyright: ( ) the author(s), publisher and licensee Medip Academy. This is an open-access article distributed under the terms of the Creative Commons Attribution Non-Commercial License, which permits unrestricted non-commercial use, distribution, and reproduction in any medium, provided the original work is properly cited.

\section{ABSTRACT}

Background: Relaparotomy in obstetrics following caesarean section or laparotomy is associated with high morbidity and mortality and hence, considered as maternal near miss. Selection of patient for the same is crucial. This study was done to know the incidence, indications, the risk factors, intraoperative procedures and mortality rates of relaparotomy.

Methods: A retrospective analysis of relaparotomy after primary obstetric surgery over a period of two and half years (June 2016 to November 2018) was done in department of obstetrics and gynecology of Rajendra Institute of Medical Sciences, Ranchi, India.

Results: During study period 28 cases of relaparotomy (18 inhouse and 10 referred cases) were identified. The incidence of relaparotomy was $0.24 \%$. Intraperitoneal hemorrhage $(39.2 \%)$ was commonest indication of reoperations followed by PPH (17.8\%), rectus sheath hematoma (14.8\%) and burst abdomen $(10.7 \%)$. Obstructed labor $(32.1 \%)$ was commonest indication of primary cesarean. Hysterectomy was required in 8 cases $(25.7 \%)$, evacuation of blood for hemoperitoneum was required in another 8 cases. Most cases of hemorrhage were reopened within 24 hours, whereas most case of the rectus sheath hematoma, burst abdomen, and broad ligament hematoma were reopened between 5-9 days.

Conclusions: Relaparotomy is often a lifesaving procedure. Decision to perform and manage relaparotomy should always be done by senior obstetricians. Meticulous surgical techniques to secure hemostasis at time of primary surgery should be adopted. Strict postoperative vigilance, is of utmost importance for early detection of intraperitoneal hemorrhage and other complications requiring relaparotomy as timely intervention.

Keywords: Cesarean section, Intraperitoneal hemorrhage, Maternal near miss, Postpartum hemorrhage, Relaparotomy

\section{INTRODUCTION}

One of the rare but serious complication of surgery is the need to perform reoperation in the postoperative period. Not only this remains a big dilemma for the surgeon, but also a crucial challenge for the patient to undergo repeat surgery within a short period of time. Relaparotomy can be classified as early or late; radical or palliative; urgent or elective. If laparotomy is done which is plannable, repeated and multiphasic to complete the primary surgery, it is not considered a relaparotomy. Laparotomy done within sixty days of primary surgery is called relaparotomy. ${ }^{1}$ Early relaparotomy are those which are done within 21 days of primary surgery. ${ }^{2}$ There has been increase in caesarean all over the world. ${ }^{3}$ This has also translated into increased risk of rare but serious complication- need for relaparotomy with high maternal mortality and morbidity, so much so that it is considered as maternal near miss (MNM). ${ }^{4}$ Therefore, selection of cases for the same is also important. Common indications for reoperations are to manage complications of previous surgery such as intra-abdominal hemorrhage, postpartum hemorrhage, rectus sheath hematoma, sepsis etc. With this background, the present study was undertaken to 
know the incidence of relaparotomy, its indications, risk factors, intraoperative procedures and mortality rates in a tertiary care teaching institution. This would help to identify the risk situations where relaparotomy might be needed and due precautions might be taken to prevent such complications.

\section{METHODS}

This was a retrospective observational study over a period of two and half years from June 2016 to November 2018 in the department of obstetrics and gynecology of Rajendra Institute of Medical Sciences (RIMS), a tertiary care teaching institution and highest referral centre for state of Jharkhand, India.

\section{Inclusion criteria}

- Cases of relaparotomy done within 6 weeks following primary cesarean section

- Cases of relaparotomy done within 6 weeks following primary laparotomy for rupture uterus or rupture ectopic.

\section{Exclusion criteria}

- Cases requiring relaparotomy after primary gynecological surgeries (abdominal hysterectomy, vaginal hysterectomy laparoscopic hysterectomy, staging laparotomy for ovarian tumor).

There was no case of relaparotomy following laparotomy for ectopic pregnancy. Total 28 cases of relaparotomy following primary caesarean section or laparotomy for rupture uterus identified during the study period and were analysed. The obstetric and demographic variables studied were: age, parity, indications of primary surgery, time interval between primary surgery and reoperation, intra-operative findings, surgical procedures done during relaparotomy and outcome of reoperations including maternal mortality.

\section{Statistical analysis}

Descriptive statistics like percentage and mean calculations were used to interpret data with the help of Microsoft office 2007.

\section{RESULTS}

During the study period of two and half years, total number of deliveries in the institution was 17,224. Out of which 7403 were cesarean section, giving C-section rate of $42.9 \%$. During the same period 28 cases had relaparotomy as per inclusion criteria. Of these, 18 cases had primary surgery at study institution itself, while 10 cases had primary surgery (cesarean) outside study institution.

The incidence of relaparotomy following institutional cesarean delivery was thus $0.24 \%$ (18/7403). The percentage of cases undergoing re-laparotomy could not be calculated for referral cases, as they came from diverse peripheral hospitals (district hospitals to private hospitals of different parts of Jharkhand) for which the total number of cesarean sections was not known.

\section{Patient profile}

Majority of the patients $(42 \%)$ were primigravida between age 19-24 years. In most of cases, primary surgery was performed between 34-40 weeks. One referred case (G3 previous 2 LSCS) had undergone hysterotomy at 18 weeks for $2^{\text {nd }}$ trimester induced abortion.

Table 1: Indications of primary surgery.

\begin{tabular}{|llll|}
\hline Indications of primary surgery & Institution $(\mathbf{n = 1 8})$ & Referred $(\mathbf{n = 1 0})$ & Total $(\mathbf{n = 2 8})$ \\
\hline CPD & 2 & 1 & $3(10.7 \%)$ \\
\hline NPOL & 3 & 1 & $4(14.28 \%)$ \\
\hline Breech & 1 & - & $1(3.57 \%)$ \\
\hline Obstructed labour/DTA & 6 & 3 & $9(32.14 \%)$ \\
\hline Prev 1 or 2 CS & 2 & 4 & $6(21.42 \%)$ \\
\hline Severe PE with complications or failed induction & 3 & - & $3(10.7 \%)$ \\
\hline Others (IVF conception and twin) & - & 1 & $1(3.57 \%)$ \\
\hline Rupture uterus following VBAC & 1 & - & $1(3.57 \%)$ \\
\hline
\end{tabular}

\section{Analysis of primary surgery}

Table 1 shows indications for primary cesarean section or laparotomy. $\quad 35.7 \%(10 / 28)$ were elective cesarean previous section 6 cases, one case each of breech, IVF conception, severe preeclampsia and cephalopelvic disproportion. Rest 18 cases (64.2\%) were emergency cesarean sections.

Obstructed labor was commonest indication of emergency cesarean in 50\% (9/18). Sepsis was associated co-morbidity in 5 cases and anemia in 10 cases. 


\section{Analysis of relaparotomy (indications, time interval and procedure performed).}

The cases were analysed on basis of indication of relaparotomy (Table 2). Intraperitoneal hemorrhage was commonest indication of repeat surgery in $39.2 \%(11 / 28)$ - 8 inhouse and 3 referred cases. Five cases $(17.8 \%)$ had reoperations for postpartum haemorrhage. One of them was a referred case of placenta accrete (increta) diagnosed intraoperatively while doing hysterotomy at 18 weeks for $2^{\text {nd }}$ trimester MTP in a woman with previous 2 cesareans. Four cases $(14.28 \%)$ had rectus sheath hematoma. We included rectus sheath hematoma in study series because we inspected peritoneal cavities as a routine in all such cases. Three cases $(10.7 \%)$ has burst abdomen. Surprisingly in all 3 cases, primary cesarean was done in-house for obstructed labour with longitudinal abdominal incision.

Table 2: Indications of relaparotomy.

\begin{tabular}{|c|c|c|c|}
\hline Indications of relaparotomy & In house ( $\mathrm{n}=18)$ & Referred (n=10) & Total $(n=28)$ \\
\hline \multicolumn{4}{|l|}{ PPH } \\
\hline Atonic PPH & 2 & 1 & \multirow{3}{*}{$5(17.85 \%)$} \\
\hline Morbid adherent placenta & - & 1 & \\
\hline Secondary PPH & 1 & - & \\
\hline Intraperitoneal haemorrhage & 8 & 3 & $11(39.2 \%)$ \\
\hline Rectus sheath hematoma & 3 & 1 & $4(14.28 \%)$ \\
\hline Burst abdomen & 3 & - & $3(10.7 \%)$ \\
\hline Abdomen distension & 1 & 2 & $3(10.7 \%)$ \\
\hline Rupture uterus & - & 1 & $1(3.75 \%)$ \\
\hline Broad ligament hematoma & - & 1 & $1(3.57 \%)$ \\
\hline
\end{tabular}

Table 3: Intraoperative procedures.

\begin{tabular}{|ll|}
\hline Procedure at relaparotomy & Number (\%) (n=28) \\
\hline Hysterectomy & $8(28.57 \%)$ \\
\hline Evacuation of hemoperitoneum and hemostasis* & $8(28.57 \%)$ \\
\hline Drainage of blood clots from under surface of rectus sheath and peritoneal cavity & $4(38.26 \%)$ \\
\hline Repair of anterior abdominal wall & $3(10.7 \%)$ \\
\hline Drainageof pus/ascites & $2(7.14 \%)$ \\
\hline Repair of uterus & $1(3.57 \%)$ \\
\hline Negative relaparotomy & $1(3.57 \%)$ \\
\hline Drainage of broad ligament hematoma & $1(3.57 \%)$ \\
\hline
\end{tabular}

*one case had splenic hilum rupture.

Table 3 summarises the intraoperative procedures performed during repeat surgery. Eight cases (28.57\%) had hysterectomy of which 5 had atonic PPH and 3 had intraperitoneal hemorrhage, but in addition to drainage of blood, these 3 cases also required hysterectomy due to flabby uterus and oozing from one of the uterine angles. In 8 cases of intraperitoneal hemorrhage diagnosed from unexplained pallor and later confirmed by ultrasonography, evacuation of hemoperitoneum with placement of intraperitoneal drain was done. Rectus sheath hematoma cases were manged by drainage of blood clots along with inspection of peritoneal cavity in all cases. In one of these cases, a third relaparotomy was required to evacuate the intraperitoneal clots from drain site. Burst abdomen cases were managed by repair of abdominal wall.

Table 4 shows details of 10 referred cases requiring relaparotomy when primary surgery was done at district hospitals or private nursing homes. One case referred to study institution in state of shock with abdominal distension turned out to be negative laparotomy as there was no intraperitoneal collection, well contracted uterus with modified B-lynch sutures in place.

Table 5 shows analysis of time interval between primary surgery and relaparotomy. Sixteen cases (57.14\%) were re-explored within 24 hours, of these 4 had primary PPH, 9 had intraperitoneal hemorrhage with pallor and shock, 2 referred cases had postoperative distension, 1 was rupture uterus following VBAC (vaginal birth after caesarean) at private nursing home. Four cases were reopened after 24 hours up to 5 days (two cases of intraperitoneal hemorrhage, 1 case of rectus sheath hematoma and 1 case of postoperative distension. But most cases of rectus sheath hematoma and burst abdomen required relaparotomy between 6-9 days. One case of broad ligament hematoma was opened on $7^{\text {th }}$ day and one case 
of slow intraperitoneal hemorrhage was reopened on $6^{\text {th }}$ day. Figure 1 shows total maternal death in study series was 8 out of 28 cases $(28.57 \%)$. Mortality rate in referred cases was $50 \%(5 / 10)$, whereas mortality in relaparotomy for inhouse primary surgery was $16.6 \%$ (3/18) only. All deaths occurred within 24 hours, except one case who died on $6^{\text {th }}$ day after cesarean due to multiorgan failure.

Table 4: Details of referred cases.

\begin{tabular}{|c|c|c|c|c|c|c|}
\hline $\begin{array}{l}\text { Pt. } \\
\text { profile }\end{array}$ & $\begin{array}{l}\text { Pr. surg and } \\
\text { indication }\end{array}$ & Ind. of relap & $\begin{array}{l}\text { Time interval } \\
\text { from previous } \\
\text { surgery }\end{array}$ & $\begin{array}{l}\text { Intraop. } \\
\text { findings }\end{array}$ & $\begin{array}{l}\text { Procedure } \\
\text { done }\end{array}$ & Outcome \\
\hline $\mathrm{G}_{3} \mathrm{P}_{2+0}$ & CS (Prev. 2 CS) & $\begin{array}{l}\text { Intra-peritoneal } \\
\text { haemorrhage }\end{array}$ & 12 hours & $\begin{array}{l}\text { Improper } \\
\text { stitching of } \\
\text { uterus }\end{array}$ & Hysterectomy & $\begin{array}{l}\text { Survived } \\
\text { LOS-10 } \\
\text { days }\end{array}$ \\
\hline $\mathrm{G}_{2} \mathrm{P}_{1+0}$ & CS (Prev. 1CS) & Atonic PPH & 4 hours & Flabby uterus & Hysterectomy & $\begin{array}{l}\text { Died after } \\
12 \text { hours, } \\
\text { DIC }\end{array}$ \\
\hline $\mathrm{G}_{2} \mathrm{P}_{1+0}$ & CS (Prev. 1CS) & $\begin{array}{l}\text { Massive } \\
\text { hemoperitoneum, } \\
\text { blood oozing } \\
\text { from abd. incision }\end{array}$ & 6 hours & $\begin{array}{l}\text { Blood oozing } \\
\text { from rt. angle }\end{array}$ & Hysterectomy & $\begin{array}{l}\text { Died after } \\
8 \text { hours, } \\
\text { DIC }\end{array}$ \\
\hline Primi & $\mathrm{CS}(\mathrm{CPD})$ & $\begin{array}{l}\text { Haemorrhagic } \\
\text { shock }\end{array}$ & 6 hours & $\begin{array}{l}\text { Negative relap } \\
\text { B-Lynch suture } \\
\text { in place }\end{array}$ & - & $\begin{array}{l}\text { Survived } \\
\text { LOS - } 7 \\
\text { days }\end{array}$ \\
\hline Primi & $\begin{array}{l}\text { Obstructed } \\
\text { labour } \rightarrow \text { rupture } \\
\text { uterus } \rightarrow \text { closed }\end{array}$ & Rupture uterus & 8 hours & $\begin{array}{l}\text { Massive } \\
\text { hemoperitoneum } \\
\text { transverse } \\
\text { rupture of LUS }\end{array}$ & Repair done & $\begin{array}{l}\text { Died after } \\
5 \text { hrs of } \\
\text { DIC }\end{array}$ \\
\hline Primi & $\begin{array}{l}\text { Obstructed } \\
\text { labour }\end{array}$ & $\begin{array}{l}\text { Abdominal } \\
\text { distension } \\
\text { (Intra-peritoneal } \\
\text { collection) }\end{array}$ & 18 hours & $\begin{array}{l}\text { Intra-peritoneal } \\
\text { pus }\end{array}$ & Drainage & $\begin{array}{l}\text { Survived } \\
\text { LOS- } 10 \\
\text { days }\end{array}$ \\
\hline Primi & $\begin{array}{l}\text { Twin preg. after } \\
\text { IVF -CS f/b } \\
\text { hysterectomy for } \\
\text { atonic } \mathrm{PPH}\end{array}$ & $\begin{array}{l}\text { Intra-peritoneal } \\
\text { haemorrhage }\end{array}$ & 4 hours & $\begin{array}{l}\text { Oozing from } \\
\text { Infundibulopelvic } \\
\text { ligament and } \\
\text { vault }\end{array}$ & $\begin{array}{l}\text { Resuturing with } \\
\text { drainage of } \\
\text { hemoperitoneum }\end{array}$ & $\begin{array}{l}\text { Died on } 6^{\text {th }} \\
\text { post-op } \\
\text { day } \\
\text { mutiorgan } \\
\text { failure }\end{array}$ \\
\hline $\mathrm{G}_{3} \mathrm{P}_{2+0}$ & $\begin{array}{l}\text { Hysterotomy in } \\
\text { Prev } 2 \text { CS for } 2^{\text {nd }} \\
\text { Trim MTP - } \\
\text { Morbid adherent } \\
\text { placenta }\end{array}$ & Atonic PPH & 5 hours & $\begin{array}{l}\text { Continued } \\
\text { hemorrhage }\end{array}$ & $\begin{array}{l}\text { Total } \\
\text { Hysterectomy }\end{array}$ & $\begin{array}{l}\text { Died after } \\
14 \text { hours, } \\
\text { multiorgan } \\
\text { failure }\end{array}$ \\
\hline $\mathrm{G}_{2} \mathrm{P}_{1+0}$ & Prolonged labour & $\begin{array}{l}\text { Rectus sheath } \\
\text { hematoma }\end{array}$ & 5 days & - & $\begin{array}{l}\text { Drainage of } \\
\text { hematoma }\end{array}$ & $\begin{array}{l}\text { Survived } \\
\text { LOS-12 } \\
\text { days }\end{array}$ \\
\hline $\mathrm{G}_{2} \mathrm{P}_{1+0}$ & $\begin{array}{l}\text { Prev. CS, obst. } \\
\text { labor }\end{array}$ & $\begin{array}{l}\text { Broad ligament } \\
\text { hematoma }\end{array}$ & 7 days & $\begin{array}{l}\text { Big hematoma in } \\
\text { right. BL, visible } \\
\text { from posterior } \\
\text { surface }\end{array}$ & $\begin{array}{l}\text { Drainage of } \\
\text { hematoma }\end{array}$ & $\begin{array}{l}\text { Survived } \\
\text { LOS- } 18 \\
\text { days }\end{array}$ \\
\hline
\end{tabular}

CS- cesarean section, pr. Surg. Primary surgery, Ind - indication, re-lap- relaparotomy, intraop- intraoperative, LOS- length of stay, BL- broad ligament

\section{DISCUSSION}

Reoperations are the life saving procedures in cases of intraperitoneal hemorrhage. Factors which can affect the outcome of relaparotomy after cesarean are indications of primary cesarean, preoperative condition, skills of operating surgeons, associated medical conditions, time interval between primary surgery and reoperations, high index of suspicion for early postoperative complications, availability of senior obstetricians and anesthetists, ICU and blood bank facilities. The cesarean section rate in the study institution was $42.9 \%$ during the study period and 
incidence of relaparotomy after inhouse primary surgery was $0.24 \%$. One such study from teaching hospital in Ghana with cesarean rate of $17.66 \%$ had relaparotomy rate of $0.7 \% .^{5}$

Table 5: Time interval between primary surgery and relaparotomy.

\begin{tabular}{|ll|}
\hline Time interval & Number $(\%)(\mathbf{n = 2 8})$ \\
\hline Within 8 hours & $7(25 \%)$ \\
\hline$>8-24$ hours & $9(32.1 \%)$ \\
\hline 1-5 days & $4(14.28 \%)$ \\
\hline $6-10$ days & $8(28.57 \%)$ \\
\hline
\end{tabular}

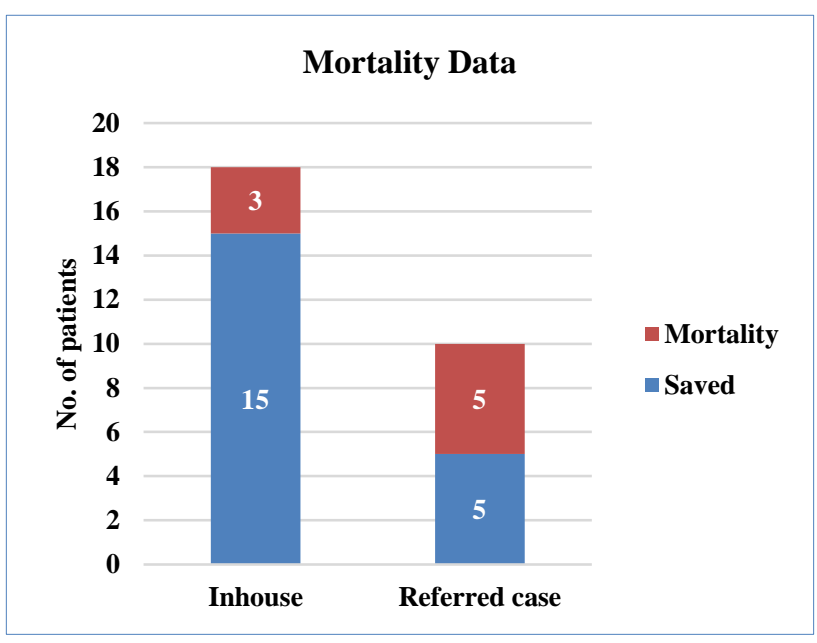

Figure 1: Maternal mortality.

A study from teaching hospital in India with cesarean rate of $34.8 \%$ has shown relaparotomy rate of $0.33 \% .^{6}$ Another study from tertiary care in Andhra Pradesh, India shows incidence of obstetric relaparotomy to be $0.11 \%{ }^{7}$ Another study from tertiary care urban hospital has shown incidence of relap to be $0.22 \%$. $^{4}$

In this study, obstructed labour was the commonest indication for primary cesarean similar to study by Seal SL et al. ${ }^{6}$ Second stage cesarean is technically difficult with increased chances of extension of uterine incision of fragile and edematous lower uterine segment. Second stage cesarean section when done by less skilled obstetricians thus have more chances of bleeding from extension of uterine incision, hematoma formation or intraperitoneal hemorrhage requiring relaparotomy. Morbidity can be reduced in $2^{\text {nd }}$ stage cesarean section by using shoulder first (Patwardhan's) method of delivery. ${ }^{8}$ Emergency surgery is major risk factor in other studies. ${ }^{6,9}$ However, significant proportion $(35.7 \%)$ in study series had elective LSCS.

Intraperitoneal hemorrhage was the most common indication of relaparotomy in study series (39.2\%) followed by $\mathrm{PPH}$ in $17.8 \%$, rectus sheath hematoma in $14.8 \%$, burst abdomen in $10.7 \%$. Similar observations were seen in other studies too. In study by Ahmed et al, reoperation was needed for hemoperitoneum in $62 \%$, rectus sheath hematoma in $28.6 \%$ and for $\mathrm{PPH}$ in $9.5 \% .^{4}$ Study by Srivastava et al also has intraperitoneal hemorrhage $(31.5 \%)$, PPH $(15.7 \%)$ and rectus sheath hematoma $(15.7 \%)$ as main indications for relaparotomy. ${ }^{9}$ However, in study by Seal et al, PPH was the commonest reason for relaparotomy in $42 \%$ followed by rectus sheath hematoma in $27.3 \%$ and hemoperitoneum in $7.58 \%$ only. ${ }^{6}$ Intraperitoneal bleeding after cesarean usually occurs from uterine incision angle due to loose suture or from retracted uterine arteries not taken care of during closure of uterine angles. Before closure of abdominal wall, posterior surface of broad ligament must be inspected for hematoma, oozers or any bleeding points. This small step would be of much help in reducing need of relaparotomy for intraperitoneal hemorrhage and broad ligament hematoma.

Kessous et al reported that hemorrhage accounted for $70 \%$ of indications for relaparotomy and additional risk factors are previous cesarean, placental abruption and cervical tear, severe pre-eclampsia. ${ }^{10}$ Lavin I et al reported that placental abruption and duration of primary surgery and experience of surgeons are significant risk factors for relaparotomy. ${ }^{11}$ In this series, however, we had no case of placental abruption as an indication for primary cesarean. Obstructed labour and previous cesarean (mostly second stage cesarean) were important risk factors. The skill of surgeon doing primary caesarean was an important risk factor requiring reoperations. One case of relaparotomy in study series, primary cesarean was done by general surgeon at district level hospital. In another case of relaparotomy where unfortunately mother died, community based maternal death review revealed that primary cesarean for obstructed labour was done at private nursing home run by quack. Cases of obstructed labor, placenta previa, previous caesarean with adhesions and suspected accrete must be done by senior skilled obstetricians. Strict guidelines should be made regarding eligibility of hospitals and qualification of doctors who can perform cesarean section.

Rectus sheath hematoma was the indication for relaparotomy in $14.28 \%$ in study series. Most of them had transverse abdominal incision. Careful suturing of rectus sheath and securing the bleeders on undersurface of rectus sheath and from rectus muscle can minimize rectus sheath hematoma. For abdominal wall hemostasis best possible closure technique include- mass closure compared to layer closure, use of absorbable monofilament suture material, a simple running suture technique and suture length to wound length ratio of $4: 1{ }^{1}$

Cases requiring relaparotomy within 24 hours were due to intraperitoneal hemorrhage or primary atonic $\mathrm{PPH}$. Similar observations were found in other studies. ${ }^{4,6}$ This reinforces the need for strict postoperative monitoring of vitals, documentation and to have high index of suspicion at the earliest to detect complications requiring relaparotomy. One case of intraperitoneal hemorrhage in 
study series was diagnosed on $5^{\text {th }}$ day when patient went into shock. On relaparotomy massive hemoperitoneum was present. No oozers or bleeders were identified from uterine angles or uterus. Surgeon was called for help then bleeding from splenic hilum was identified and secured. Ahmed et al reported 3 cases of second relaparotomy in their series (one each for wound infection, colostomy closure and hemoperitoneum). Seal et al reported need for second relaparotomy in 11 cases of secondary PPH in an effort to conserve uterus in first relaparotomy ultimately requiring second relap for hysterectomy. We did not have any case of second relap for 5 cases of PPH as hysterectomy was done in all these cases in first relaparotomy. This study has one case of second relaparotomy, done in a case of rectus sheath hematoma due to intraperitoneal collection of blood from inner edge of drain site. While putting intraperitoneal drain precaution should be taken to pass drainage tube through peritoneum and sheath only avoiding rectus muscle.

Maternal mortality rate in study series was relatively higher $28.5 \%(8 / 28)$. If we look at death rate in referral cases, it was $5 / 10(50 \%)$ whereas in cases of inhouse relaparotomy it was $3 / 18(16.6 \%)$. All deaths occurred within 24 hours except one case on $6^{\text {th }}$ day due to multiorgan failure. This again reinforces the need for strict postoperative vigilance and timely referral to manage complications. Maternal death occurred in 3 cases of in-house deliveries. One case of atonic PPH was managed with medical measures and balloon tamponade with aim to conserve uterus. Ultimately hysterectomy was done 18 hours after delivery to manage atonic PPH, but patient succumbed to death. This case gives us the lesson, that quick and timely decision for hysterectomy as life saving measure after proper counselling of patient attendants may help to prevent maternal death. Another woman went into irreversible shock, was identified too late (after 6 hours) in postoperative period. Maternal death review revealed that she remained unattended due to casual approach of junior residents during postoperative vitals monitoring. Third case was found to have massive ascites on relap, who finally succumbed to death. Mortality rate in other studies vary from as low as $2.8 \%$ in study by Ahmed et al to high rate of $12.1 \%$ and $15.78 \%$.,6,12 $^{4,12}$

\section{CONCLUSION}

Relaparotomy following cesarean section is considered a near miss mortality. Most of the time it is a lifesaving procedure. Decision to perform and manage relaparotomy should always be multidisciplinary team approach with senior obstetricians and senior anaesthesiologists, as these patients are usually in state of shock with multiorgan dysfunction and sepsis.

Meticulous surgical technique to secure haemostasis at time of primary surgery especially careful suturing of uterine angles, putting intraperitoneal drain wherever indicated, visualising posterior surface of broad ligament for any hematoma or bleeders are important to prevent the need for relaparotomy. Cases of obstructed labour, placenta previa, accrete should be supervised by senior consultants rather than done by residents. Time interval between primary operative procedure and relaparotomy is the most significant factor deciding outcome. Strict postoperative vigilance, documentation of vitals in postoperative period is of utmost importance for early detection of intraperitoneal haemorrhage and other complications requiring relaparotomy. Finally lowering the primary cesarean rate will definitely lead to reduction rate of its complications including relaparotomy. Unnecessary cesarean should be avoided. Increasing trends of cesarean section, surgery at peripheral centres by less skilled obstetricians, non-availability of blood bank increases the complications such as need for relaparotomy. Timely referral in these cases before patient goes in irreversible shock will reduce the complications of relaparotomy including mortality.

\section{Funding: No funding sources \\ Conflict of interest: None declared \\ Ethical approval: Not required}

\section{REFERENCES}

1. Unalp HR, Kamer E, Kar H. Uurgent abdominal reexplorations. World J Emerg Surg. 2006;1:10.

2. Sar ME, Turgut A, Evsan MS, Soydine HE, Ozer A, Sak S, et al. Relaparotomy after initial surgery in obstetric and gynaecology operations: analysis of 113 cases. Ginekol Pol. 2012;83:429-32.

3. Joseph KS, Young DC, Dodds L. Changes in maternal characteristics and obstetric practice and recent increases in primary cesarean delivery. Obstet Gynecol. 2003;102(4):791-800.

4. Ahmed M, Pandya ST, Supranani T. Return to operation theatre: an analysis of repeat surgeries in operative obstetrics. J Obstet Gynaecol India. 2016;66(51):5117-21.

5. Seffah JD. Relaparotomy after cesarean. Int J Gynecol Obstet. 2005;88:253-7.

6. Seal SL, Kamilya G, Bhattacharya SK, Mukkerji J, Bhattacharya AR. Relaparotomy after cesarean delivery: experience from an Indian teaching hospital. J Obstet Gynecol Res. 2006;33(6):804-9.

7. Jhambarapu U, Kodey PD, Koneru GR. Retrospective study of relaparotomy in department of obstetrics gynaecology and family planning in rural tertiary care hospital, Andhra Pradesh, India. Int J Med Res Health Sci. 2015;4(3):582-6.

8. Kumari A. Reducing morbidity in second stage caesarean section by Patwardhan's (shoulder first) method of delivery. Int J Reprod Contracept Obst Gynecol. 2018;7:2208-11.

9. Srivastav P, Qureshi S, Singh U. Relaparotomy: Review of indications and outcome in tertiary care hospital. Int J Reprod Contracept Obstet Gynecol. 2016;5(2):520-4. 
10. Kessous R, Danor D, Weintranl YA. Risk factor for Relaparotomy after cesarean section. J Matern Fetal Neonatal Med. 2012;25(11):2169-70.

11. Lavin I. Rapaport AS, Satzer L. Risk factors for relaparotomy after cesarean delivery. Int J Gynecol Obstet. 2012;119(2):163-5.

12. Dasgupta S, Sharma PP, Kalra A, Mukhopadhyay P, Mahajan K, Dasgupta S. Early reoperatios after gynecological and obstetrical surgery-a five years study. J Obstet Gynecol India. 2010;60(6):507-10.

Cite this article as: Kumari A, Vidyarthi A. An analysis of relaparotomy in operative obstetrics. Int $\mathbf{J}$ Reprod Contracept Obstet Gynecol 2020;9:1813-9. 